\title{
Joint Paediatric and Psychiatric Follow-Up for Families following Paediatric Intensive Care Unit Admission: An Exploratory Study
}

\author{
Julia Gledhill, ${ }^{1}$ Amina Tareen, ${ }^{2}$ Mehrengise Cooper, ${ }^{3}$ \\ Simon Nadel, ${ }^{3}$ and M. Elena Garralda ${ }^{4}$ \\ ${ }^{1}$ Central and North West London NHS Trust and the Academic Unit of Child and Adolescent Psychiatry, Imperial College London, \\ St Mary's Campus, Norfolk Place, London W2 1PG, UK \\ ${ }^{2}$ Barnet, Enfield and Haringey Mental Health Trust, London N2 8LT, UK \\ ${ }^{3}$ Department of Paediatric Intensive Care, St Mary's Hospital, Imperial College Healthcare NHS Trust, London W2 1NY, UK \\ ${ }^{4}$ Academic Unit of Child and Adolescent Psychiatry, Imperial College London, London W2 1PG, UK
}

Correspondence should be addressed to Julia Gledhill; j.gledhill@imperial.ac.uk

Received 23 April 2014; Accepted 25 May 2014; Published 4 June 2014

Academic Editor: Rosalind Elliott

Copyright (C) 2014 Julia Gledhill et al. This is an open access article distributed under the Creative Commons Attribution License, which permits unrestricted use, distribution, and reproduction in any medium, provided the original work is properly cited.

Psychopathology in parents and children is increased after Paediatric Intensive Care Unit (PICU) admission; few studies have evaluated interventions to reduce this. Objective. Evaluation of the feasibility of setting up a joint paediatric and psychiatric followup clinic for families after PICU discharge. Design. Feasibility study offering joint follow-up with a consultant paediatric intensivist and child and adolescent psychiatrist. Setting. Paediatric outpatient clinic in a university teaching hospital with a PICU. Patients. Children and their families discharged from PICU. Interventions. Outpatient appointment focussing on physical and psychological health; psychoeducation about emotional and behavioural difficulties occurring after PICU discharge, advice for parents about supporting their child's psychological recovery, screening for more severe psychiatric disorders, and provision of a leaflet outlining possible difficulties and management strategies. Measurements. Attendance, content of discussion, psychiatric questionnaires, and family feedback. Main Results. It proved feasible to set up follow-up appointments to address physical and psychological health concerns; 4/12(33\%) eligible families attended. Children and mothers who attended all reported child difficulties including sleep disturbance, increased anxiety, and PTSD symptoms in children and parents. Conclusions. Follow-up clinics after PICU discharge are feasible to set up; take-up is poor but families attending report psychopathology which may be addressed through the intervention.

\section{Introduction}

There is accumulating evidence of increased risk of psychopathology, particularly but not exclusively posttraumatic stress disorder (PTSD), in children and parents following PICU admission [1-6]. Critical illness impacts on parenting $[3,7]$ and parental PTSD is associated with poorer psychological recovery in the child [8].

Although National Institute for Clinical Excellence (NICE) Guidelines [9] advocate continued monitoring and support of patients and families after intensive care treatment, follow-up is infrequent [10]. Mothers favour follow-up by the PICU team to talk through the admission and believe that this may be psychologically beneficial [11]. However, little work has evaluated the effectiveness of psychological interventions.

An American randomised controlled study demonstrated the effectiveness of a combination of psychoeducation for mothers during the child's admission and parental activities with their children to help them make sense of their experience, in improving maternal functioning and emotional wellbeing and reducing child adjustment problems/behavioural difficulties a year after discharge [12]. However the findings must be interpreted in the context of over $50 \%$ attrition 
at follow-up and generally small effect sizes. A subsequent British study [10] offered follow-up with a PICU consultant, senior nurse, and/or psychologist two months after discharge; appointments were only taken up by a quarter of families, but there were benefits on rates of depression and posttraumatic stress symptoms in the subgroup of parents with high levels of stress at hospital discharge.

\section{Aims}

This study assesses the feasibility of setting up and evaluating the take-up of a joint paediatric/child psychiatric educational follow-up service for families 6 weeks after PICU discharge. A secondary aim was to obtain feedback from families about utility.

Ethical approval was obtained from St Marys Local Research Ethics Committee.

\section{Method}

The study took place at St Mary's Hospital, London, which, at the time of the study, had a 10-bedded PICU with approximately 500 admissions a year; reasons for admission were broad and included all causes of critical illness in children. After discharge, follow up by the PICU team was not routine.

Recruitment took place between January and August 2005 with a further month in January 2006. Families with a child over 8 years discharged from PICU were eligible and were offered a joint hospital outpatient appointment with a senior paediatric intensivist with a paediatric background and child psychiatrist six weeks after discharge. Families speaking insufficient English to complete the study questionnaires and those with underlying neurological disease were excluded.

The Intervention Appointment. The child's physical condition was assessed by the intensivist; families were next given an opportunity to speak to the paediatrician and psychiatrist jointly for half an hour and then continue meeting with the child psychiatrist. The first part of the meeting focused on physical health concerns and clarification of queries about PICU treatment. The meeting with the child psychiatrist included imparting information (psychoeducation) about emotional and behavioural problems that may occur after PICU admission; simple advice about managing psychological symptoms (largely using behavioural interventions and particularly targeting PTSD symptoms, anxiety, and behavioural problems), such as gradually exposing children to anxiety-provoking situations associated with the admission that they may be trying to avoid, parents maintaining firm boundaries with regard to their child's behavior, and keeping regular routines at home, for example, around bedtime; providing an opportunity to identify more severe psychiatric problems through history and clinical assessment and facilitating appropriate referral to local child and adolescent mental health services (CAMHS) if appropriate; families were given a leaflet about possible psychiatric presentations and management strategies (see Appendix). They were also
TABLE 1: Child characteristics for the 4 families who attended the follow-up appointment.

\begin{tabular}{lccc}
\hline Age (years) & Gender & $\begin{array}{c}\text { Length of PICU } \\
\text { stay (days) }\end{array}$ & Diagnosis \\
\hline 11 & Male & 2 & Status asthmaticus \\
11 & Female & 18 & Respiratory failure \\
12 & Female & 5 & Tuberculosis \\
13 & Male & 1 & Status asthmaticus \\
\hline
\end{tabular}

given contact numbers for the child psychiatrist and paediatrician they saw in case of ongoing concerns.

Outcome Measures. Used to assess child and parental psychopathology and consisted of standardized well-validated screening questionnaires including the following: the Strengths and Difficulties Questionnaire (child psychiatric adjustment) [13], The General Health Questionnaire [14] (parental psychiatric disorder), and the Impact of Events Scale [15] (PTSD symptoms in children and parents).

Feedback from families regarding the appointment was requested 3 months after discharge using a questionnaire designed for the study with 5-point Likert scales to quantify how useful the family found the meeting and the leaflet.

\section{Results}

Of 14 eligible families 12 were contactable; 4(33\%) attended appointments. Four families failed to respond to the invitation, and 4 declined to attend: two because the travel distance to the hospital was too far; one family noted they wanted to return to a normal life; one parent declined saying she had symptoms but was unable to face coming to the appointment.

In the 14 families approached, the median age of the child (7 boys, 7 girls) was 11 years (range 8-14), and median length of PICU stay was 3 days (range 1-18). Admission diagnoses were asthma (6), infectious diseases (8), seizures (2), and diagnosis not documented (2). Both parents were invited; only mothers attended. There was no significant difference between the 4 participating and the other 10 families with regard to gender, age, and length of PICU stay. Demographic and illness data for children from the 4 attending families are shown in Table 1.

Of the 4 families who attended, none had major physical health problems; all reported and discussed psychological difficulty in the child. Three had sleep problems (i.e., difficulty getting to sleep, nightmares, and anxiety about sleeping alone; two children were sleeping in their mother's bed: one for 6 weeks after discharge and the other still doing so at followup). Two children displayed anxiety; separation anxiety(1) and in another anxiety linked with experiencing similar physical symptoms to those that had led to admission. PTSD avoidant symptoms were reported for two children, including not wanting to be reminded of the hospital and becoming upset when this was spoken about; another child refused to attend hospital when physical symptoms developed after 
discharge. Mixed behavior/oppositional/anxiety symptoms were reported for one child.

All attending mothers experienced psychological difficulties, which they discussed. These included anxiety about their child becoming unwell again, manifested as checking on them more frequently than prior to the illness, anxiety if their child was late home from school, and "panic" if the school telephoned for any reason. Two parents also reported intrusive and avoidant PTSD symptoms including flashbacks, avoidance of thoughts and places linked with the admission, avoiding talking or thinking about the admission, and hypervigilance with regard to their child, such as watching them closely when playing outside. Psychiatric questionnaires were only completed by 2 families and were therefore not considered further. One family returned the feedback questionnaire, strongly agreeing that the meeting and advice in the leaflet had been useful and that this type of appointment should be offered to all families.

\section{Discussion}

It is feasible to arrange a joint psychiatric/paediatric outpatient follow-up appointment for families following PICU discharge. This was taken up by one-third of families approached; all families attending reported and discussed psychological sequelae.

All attending mothers reported child difficulties including sleep disturbance, increased anxiety, and PTSD symptoms in both children and parents. This is in-keeping with the PICU follow-up intervention by Colville et al. [10] and with studies which have documented high levels of psychiatric symptoms in children and parents following critical illness [1-6]. Parents more stressed at hospital discharge were more likely to attend and benefit from the psychological follow-up [10], suggesting that interventions are addressing an unmet need.

These findings may help inform future interventions. To increase accessibility to psychoeducation, written information about possible psychological sequelae after discharge may be preferable, complemented by telephone support and guidance. To address specific psychopathology such as PTSD which is associated with abnormal processing and poor organization of autobiographical memories [16], parental completion of diaries during PICU admission, as reported by adult Intensive Care Units [17], is worth exploring. Finally, special attention could be helpfully focused on identification of families at high risk for mental health sequelae and interventions targeted at this group through facilitating contact with local paediatric/CAMHS services.

\section{Appendix}

Leaflet: Readjusting to Family Life after PICU Admission

St Mary's Hospital PICU and Imperial College London

Admission to PICU. Having a child admitted to PICU can be a very frightening experience for children and their parents. Whilst in the PICU there may be concerns about whether children will survive at all or whether they will be left with disabilities or continuing illness. Parents frequently say that having nurses and doctors close at hand to answer their questions or worries is very helpful and feel that this is very supportive whilst they are in PICU. However, when children come out of PICU onto a paediatric ward to go home there may be other worries, such as whether the illness is going to come back or whether their child will ever return to normal.

Given the shock of the experience it is not surprising that some children show changes in their behaviour. It is also an entirely new situation for parents who may feel unsettled by these changes and be left wondering whether they are permanent and how to manage a child who has been so critically unwell. Many parents feel shocked by the whole experience and some feel guilty about being upset themselves, as they think they should be strong to help their child recover.

When parents ask doctors or nurses about these things, we usually say that some behavioural changes are to be expected after such a severe illness and that over time as the child recovers these behaviours should also disappear. This is true for many but not all children.

Most children who have been in PICU make a full recovery and on average are back to school within a few weeks of leaving hospital. However, a proportion of them become fearful and tearful or seem to develop worries. Others become restless and overactive and have difficulty in concentrating.

As many as one in five children are very distressed by their admission to PICU after they go home and suffer bad dreams or very vivid memories of the admission. They may try to avoid situations that remind them of what happened, for example, going back to the hospital for an outpatient appointment. In most cases these symptoms improve over the following six months, but a third of children are still left trying not to think about the admission or avoiding reminders and up to a half are generally more irritable than before they got ill.

With time children tend to become less fearful and worried. The restlessness and poor concentration also diminish. However, the more severely ill the child has been, the longer they may take to recover.

This Leaflet is designed to give some suggestions to parents who are worried about their child's behaviour after a severe illness that needed PICU admission. These simple, practical suggestions will be helpful for many children.

\section{What Can Parents Do to Help Their Child?}

Anxious Behaviour. When anxious, children might want to avoid quite a lot of things that they associate in their minds with what they have gone through. They might be obvious things like going to the hospital for a check-up or might be less obvious ones such as not wanting to play in the garden as that is where they were when they got ill. Anxious children need comfort and reassurance but they also need parents who can stay calm and firm and help them overcome their fears and difficulties. The right approach is important because otherwise the fears may limit them in things they are able to do or enjoy, both now and in the future. 
This does not mean forcing them to face situations that they are afraid of head on but rather approaching them in a gradual and stepwise way, so children are able to manage without feeling overwhelmed. We will have discussed possible ways of going about this during our follow-up meeting at the hospital.

\section{"I am still feeling upset about what happened-} how can I help my child?"

Quite a few parents are distressed by the experience they and their child have gone through and have similar difficulties, themselves. They might be keen to put the memories of the PICU behind them as soon as possible and so try to ignore their feelings of anxiety or their nightmares. This can lead them to actively avoid talking about what the family has been through. Children may sense this and in turn avoid referring to the hospital admission or to any fears they may have developed. Parents may wish to avoid reminders of the event, and this can make it especially hard for them to tackle their child's avoidance.

Some parents might unfairly blame themselves or feel guilty for being upset and believe they should be able to "get on with things." This could take the form of giving themselves permission to cry or get upset or explore their feelings and memories of the experience with a close friend or relative. Parents may need to put their PICU experience into words by writing it out or having time to recall it in detail and then, similar to what we have already suggested for children, replace the upsetting thoughts with ones that give them a sense of control.

\section{"I do not want to be too strict. (S)he's been so unwell."}

The importance of setting clear boundaries for children's behaviour should not be underestimated. Parents are often worried about doing this because of the effect it may have on a child who has been so unwell. Some degree of irritability and stubbornness or refusal to do as asked can be ignored, but behaviours that parents considered nonnegotiable before the illness should still remain within consistent boundaries. Consequences for unacceptable behaviour should be similar to what they were before the child became unwell; ideally the consequences should be immediate and quite short lived, for example, withdrawal of TV or play station privileges for a short period (maybe up to one hour, depending on the age of the child).

"(S)he can't focus on her schoolwork at the moment."

After discharge from hospital, it can get difficult for children to settle down and concentrate and some find it quite difficult to manage at school. This tends to be temporary, though it can take a few months for children to come out of it. It will be more of a problem for adolescents, especially around exam times. Teachers tend to be sensitive to this and can helpfully give short tasks as well as breaks in between tasks. Extra time during exams may also be helpful. If your child is having difficulties of this kind in school, it might be useful for you to share this leaflet with your child's teachers.
"(S)he keeps having nightmares and cannot get to sleep."

Some children become frightened of going to sleep. They may not be able to say why this is. However, some develop nightmares. These bad dreams are not always to do with the hospital experience and may just be upsetting dreams. Some children will want to sleep in their parent's bed. It is often helpful to keep to the regular routine of bedtimes but provide extra comfort, maybe staying with the child a bit longer to settle them.

"So what does this mean for my family?"

(i) The experience of PICU admission is usually stressful for children and families.

(ii) Some children and parents develop emotional distress, fears, and avoidance of situations related to the admission after discharge.

(iii) Some children can become restless, moody, and stubborn.

(iv) We have tried to suggest some simple things parents can do to help their child and themselves get over these difficulties.

(v) For many families, this will be enough; some may like a bit more help.

(vi) If you feel you would like further help, you could contact your GP (we will have informed him of this study) or call us on the number below and we can help you get the right sort of help.

\section{Conflict of Interests}

The authors declare that there is no conflict of interests regarding the publication of this paper.

\section{Acknowledgments}

The authors are grateful to all the children and parents involved with this study.

\section{References}

[1] G. Rees, J. Gledhill, M. E. Garralda, and S. Nadel, "Psychiatric outcome following paediatric intensive care unit (PICU) admission: a cohort study," Intensive Care Medicine, vol. 30, no. 8, pp. 1607-1614, 2004.

[2] G. A. Colville and C. M. Pierce, "Children's self-reported quality of life after intensive care treatment," Critical Care, vol. 14, supplement 1, p. 438, 2010.

[3] D. Shears, S. Nadel, J. Gledhill, F. Gordon, and M. E. Garralda, "Psychiatric adjustment in the year after meningococcal disease in childhood," Journal of the American Academy of Child and Adolescent Psychiatry, vol. 46, no. 1, pp. 76-82, 2007.

[4] D. S. Davydow, L. P. Richardson, D. F. Zatzick, and W. J. Katon, "Psychiatric morbidity in pediatric critical illness survivors: a comprehensive review of the literature," Archives of Pediatrics and Adolescent Medicine, vol. 164, no. 4, pp. 377-385, 2010. 
[5] A. Balluffi, N. Kassam-Adams, A. Kazak, M. Tucker, T. Dominguez, and M. Helfaer, "Traumatic stress in parents of children admitted to the pediatric intensive care unit," Pediatric Critical Care Medicine, vol. 5, no. 6, pp. 547-553, 2004.

[6] M. E. Garralda, J. Gledhill, S. Nadel, D. Neasham, M. O'Connor, and D. Shears, "Longer-term psychiatric adjustment of children and parents after meningococcal disease," Pediatric Critical Care Medicine, vol. 10, no. 6, pp. 675-680, 2009.

[7] G. Colville, J. Darkins, J. Hesketh, V. Bennett, J. Alcock, and J. Noyes, "The impact on parents of a child's admission to intensive care: integration of qualitative findings from a crosssectional study," Intensive and Critical Care Nursing, vol. 25, no. 2, pp. 72-79, 2009.

[8] M. A. Landolt, E. Ystrom, F. H. Sennhauser, H. E. Gnehm, and M. E. Vollrath, "The mutual prospective influence of child and parental post-traumatic stress symptoms in pediatric patients," Journal of Child Psychology and Psychiatry, vol. 53, no. 7, pp. 767774, 2012.

[9] NICE, Rehabilitation after Critical Illness, National Clinical Practice Guideline, no. 83, National Institute for Health and Clinical Excellence, London, UK, 2009.

[10] G. A. Colville, P. R. Cream, and S. M. Kerry, "Do parents benefit from the offer of a follow-up appointment after their child's admission to intensive care?: an exploratory randomised controlled trial," Intensive and Critical Care Nursing, vol. 26, no. 3, pp. 146-153, 2010.

[11] G. A. Colville and D. Gracey, "Mothers' recollections of the Paediatric Intensive Care Unit: associations with psychopathology and views on follow up," Intensive and Critical Care Nursing, vol. 22, no. 1, pp. 49-55, 2006.

[12] B. M. Melnyk, L. Alpert-Gillis, N. F. Feinstein et al., "Creating opportunities for parent empowerment: program effects on the mental health/coping outcomes of critically ill young children and their mothers," Pediatrics, vol. 113, no. 6, pp. e597-e607, 2004.

[13] R. Goodman, "The strengths and difficulties questionnaire: a research note," Journal of Child Psychology and Psychiatry, vol. 38, no. 5, pp. 581-586, 1997.

[14] D. Goldberg, The Detection of Psychiatric Illness by Questionnaire, Oxford University Press, Oxford, UK, 1972.

[15] M. Horowitz, N. Wilner, and W. Alvarez, "Impact of event scale: a measure of subjective stress," Psychosomatic Medicine, vol. 41, no. 3, pp. 209-218, 1979.

[16] A. Ehlers and D. M. Clark, "A cognitive model of posttraumatic stress disorder," Behaviour Research and Therapy, vol. 38, no. 4, pp. 319-345, 2000.

[17] R. E. Knowles and N. Tarrier, "Evaluation of the effect of prospective patient diaries on emotional well-being in intensive care unit survivors: a randomized controlled trial," Critical Care Medicine, vol. 37, no. 1, pp. 184-191, 2009. 


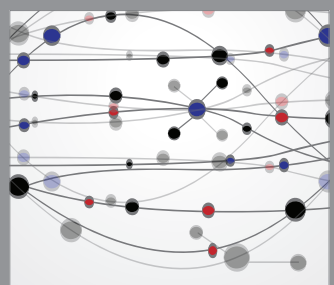

The Scientific World Journal
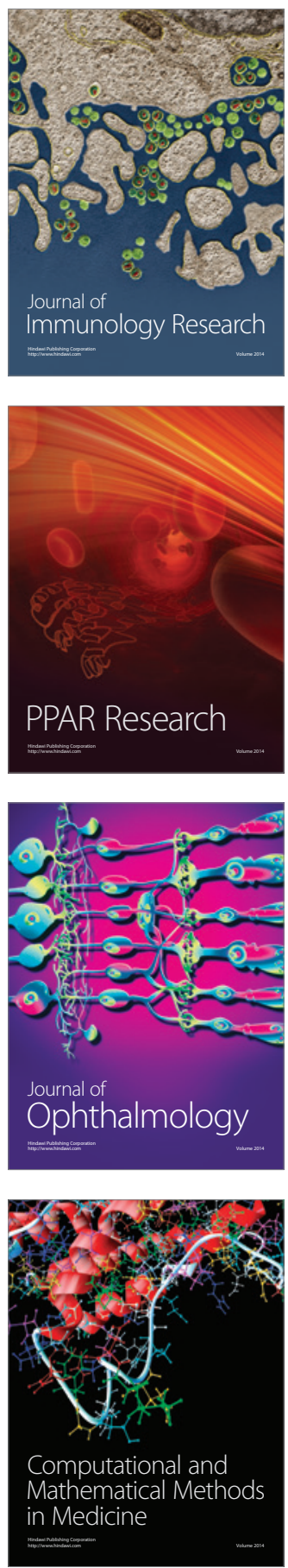

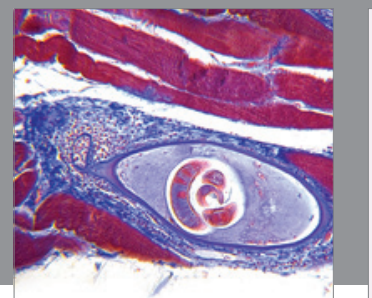

Gastroenterology

Research and Practice
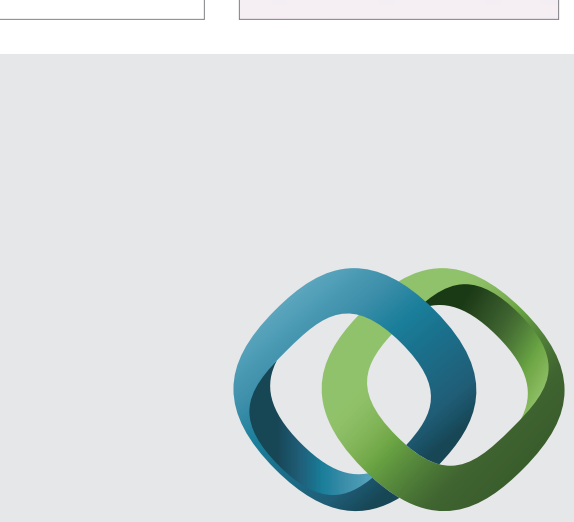

\section{Hindawi}

Submit your manuscripts at

http://www.hindawi.com
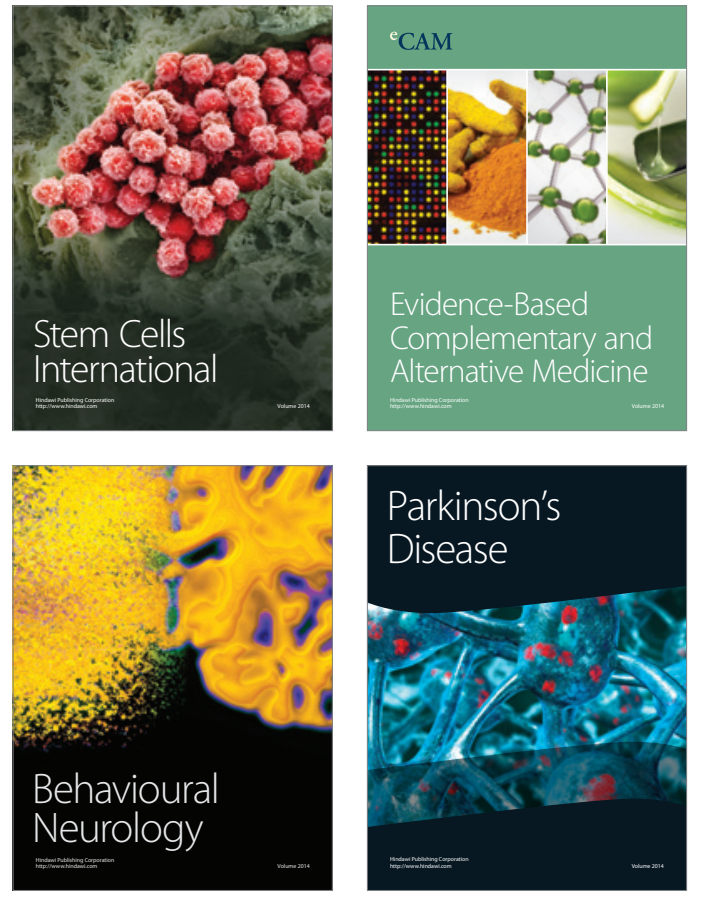
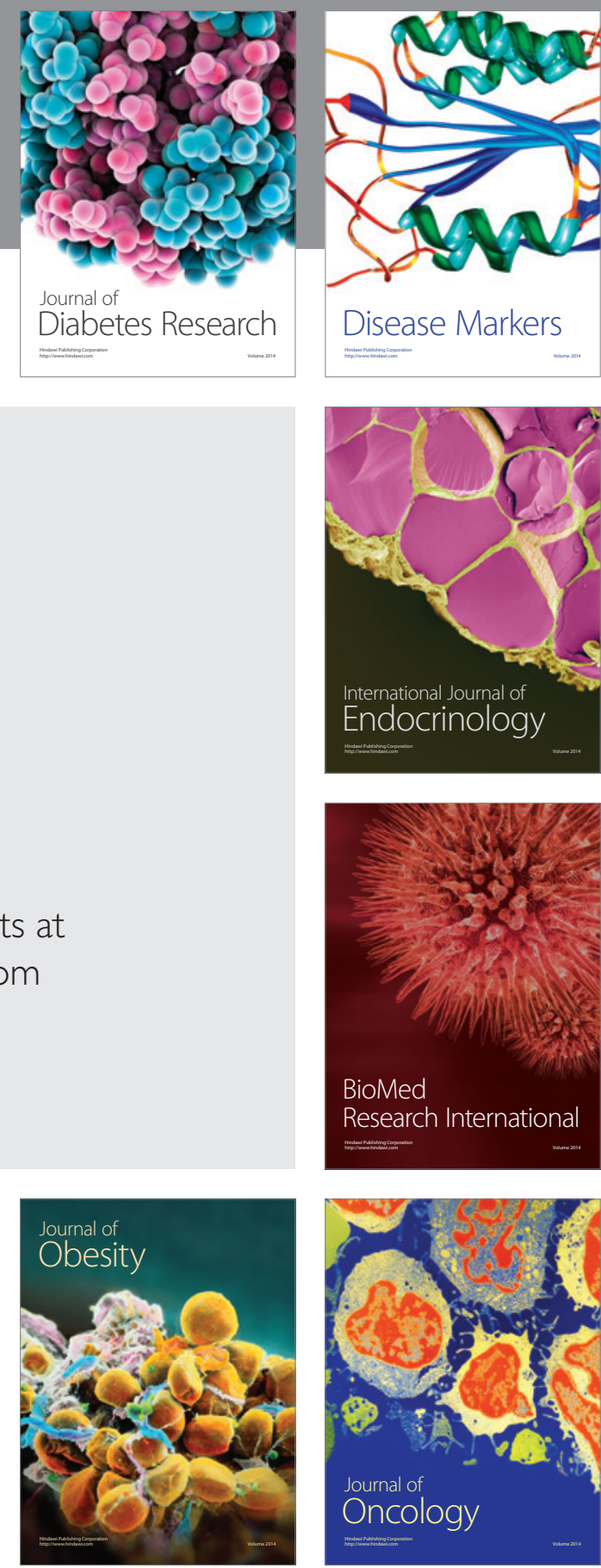

Disease Markers
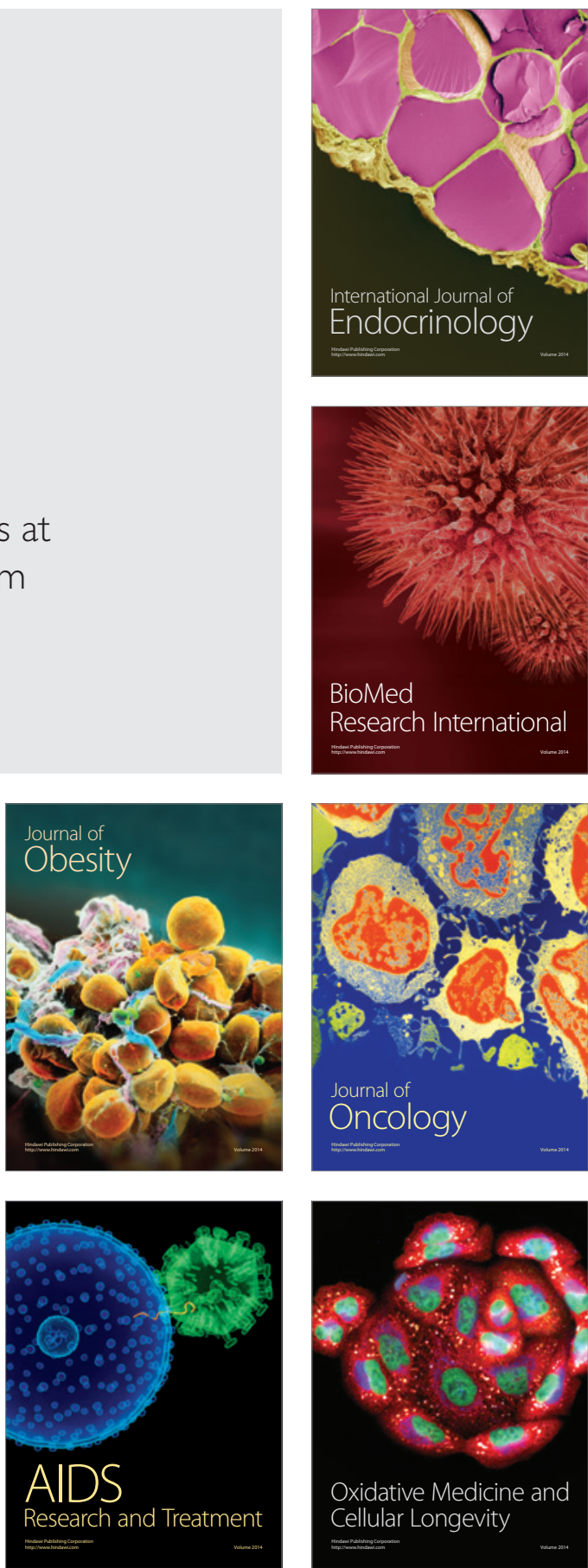